\title{
The Semantic Conditionality of the Regional Perception of Space: Perceptual-spatial Connection of Functionally Integrated Elements of Culture
}

\author{
Irina Sovetovna Karabulatova1
}

Ilya Vyacheslavovich Dukov2

Svetlana Dmitrievna Galiullina ${ }^{3}$

Lydia Mihaylovna Stratonova ${ }^{3}$

Zishana Memetovna Abdullina ${ }^{3}$

${ }^{1}$ Institute of Social and Political Research of the Russian Academy of Sciences, 32A, Leninsky prospect, Moscow ${ }^{2}$ Russian Academy of Arts, Sculpture and Architecture llya Glazunov, Moscow ${ }^{3}$ Ufa State University of Economics and Service, 450078, Ufa, Chernyshevsky St., 145

\section{Doi:10.5901/mjss.2015.v6n6s3p36}

\section{Abstract}

\begin{abstract}
Search for new mythological and philosophical establishments in modified geopolitical conditions make another treatment to the phenomenon of space, perception and his refer to human civilization. The magnitude and intenseness are taking place in our society of social and economic processes; they determine an essential increase of role of the human factor for successful conclusion of the initiated reforms. The humanity always aspires to fill the world around of objects. There are complicated and monumental things like a town, and there are relatively simple and not great, for example, picture. The whole world of objects stays in space, if it was created and functionally-integrated by person, or uncreated, natural. This article reviews a problem of the connection of objective elements of culture in the space of the world. Talking about any subject of art, we are thinking it in the field positioned in a certain space. Moreover, it touches not only visual subjects but also things are perceived by organs of smell, touch and taste. All things are thought wrapped up in space. Herewith, socio-psychological inquiries of communication, including investigation of cognitive processes of each other, assume particularly important significance. Since ancient times, people were interested in a question what is the phenomenon of space? If it has something absolutely empty or it is some ethereal body. If it's possible to exist without objects or it appears especial in time when objects appear. What is the first: body or space?
\end{abstract}

Keywords: semiotic, culture, space, perception, landscape.

\section{Introduction}

Perception of space is an imaginative reflection of the spatial characteristics of the surrounding world, the perception of the size and shape of objects, their mutual arrangement, where is especially significant taking part visual, motor, skin and vestibular analyzers. The perception of space is based on measurements of distances and angles in a surrounding space, which are realized by active movements in the control exercised by the organs of senses. (Helmholtz, Sechenov). We need in an asymmetry of human body for separate the sensory areas up and down, forward and backward, left and right. In the capacity of a starting point in the perception of space is an individual bodily organization. In particular sensations coming from the machine equilibrium, forming perception up and down in a direction indicate about deviation of the position of the body when the vertical axis of body is flatwise to ground. At the coast of working mechanisms of spatial vision forms a depth perception, distantly.

In the perception of the object as a kind of synthesis of its properties is a reaction to a complex irritant, reflex to relation between his qualities. As a result, the subjective perception of having images of objects - views. The process of perception takes place in conjunction with other human mental processes: mentation (we perceive an object of perception) by language (call the word), feelings (show our attitude to it) will (conscious effort to organize perceptual activities).

An important role in the perception play emotional states of man, his aspirations, troubles of content. Emotions appear as a motive, the internal desire for knowledge of objects and phenomena (Delez, 1998). Huge areas as a rule 
have a various and multiple-vector network of associations that support a variety of associative fields in the perception of the individual (Karabulatova, 2008; Potebnya, 2000 Karabulatova, Fedorova \& Sayfulina, 2014 \& Gilazov, Karabulatova, Sayfulina, Kurakova \& Talipova, 2015).

Today, in new independent states had formed on the fond of the Soviet Union, we can see a splash of new myth coinage, due to the awareness of itself own geopolitical significance, the formation of civic, state, ethnic identity, where the designation of the space is the main myth-forming and state-forming component: "Astana - is the heart of Eurasia", "Moscow -is the third Rome "," Ukraine - Ukraine-Rus ", etc. The idea is not new, it is enough to remember the "New York - is a big apple," "Paris -is the city of love," "Las Vegas - is the city of sin," etc. This is myth-making on the perception of space touches the most deep structures of human soul, forming, by definition B. Anderson, ' imaginative communities' (2001). The productivity of the perception of objects and phenomena of the world play an important role for activity, human effectiveness. It is manifests in the work of the senses, aimed at perceived objects, in their palpation examination by vision inspection of circuits, different parts. This is seen both in the perception of the natural landscape (look at toponyms: Round Lake, Lake Bowl, river Krivulya), and also in the perception of the cultural landscape created artificially by man (for example, the square Lubyanka - Bald Mountain in the Moscow, "Chupa Chups" - is a Square of Fiendship in Dalian, or a monument of Chupa Chups - is a Baiterek in Astana).

The perception in relation to the mental life of man acquires a special significance. The object of perception can specifically affect the intellectual or the emotional side of the known object or phenomenon. Scientific knowledge is needed in an intellectual perception, that is, in a perception of content, understanding of concepts and terms used to perform action, enhanced action of memory, attention, and mentation. Emotional perception is clearly appears in case of perception works of art in the art. Formulated differently "imagination is not just some spontaneous, productive ability in the Kant's opinion, and value notions - are not just creations of the human mind, as they, in fact, Weber had. The man initially characterized by the need for value orientations "(Anderson, 2001: 11).

Recently, however, the imagination have become the decisive factor in the self-determination of man primarily national. Today, nationalism, ethnocentrism becomes a kind of religion in modern society, offering to man "immortality at fair price": the nation is eternal, so I'm eternal too, because I'm a part of the nation. There are proper names, especially ethnonyms, toponymes serve as storage archetypes of human, and it was clearly aware of the policy. For example, in the "Concept of the State onomastic work in the Republic of Kazakhstan" dated January 21, 2005 № 45 noted that "such names as Turkistan, Astana, Baikonur, Karashyganak et al., Included in onomastic space of Kazakhstan, being closely linked with the economy, history and culture of Kazakhstan, have not only address's function, but also they are highly associative semiotic signs, involving the powerful national potential. "The notion that the name - it is a symbol of the country, used in the competition «Name - Russia», where chooses the names - symbols of Russia: Mendeleev, Suvorov, Peter the Great, and others. The authors of the competition line thus symbolic names, their sign, which is especially becoming relevant in the "dark years."

With this perception, the main role plays emotional side, a direct influence on the perceived object to moral, aesthetic sense. Of course, the artistic sensibility is carried out in unity with the intellectual. Conception what is perceived, it is a necessary prerequisite, but an emotional trouble in an artistic perception defines his character: sublimate or subdued mood, emotions of high, comic, tragic, that it excites the perceived material. Therefore, the perception of the content - is a perception of space (Kobersy at el., 2015), movement, time. In the perception of space, movement and time take part greater or smaller different analyzers in their interconnection.

The perception of space comes with visual, kinesthetic and auditory analyzers. Object of spatial perception - is a differentiation of sizes and shapes of objects, distances, their placement in the space, the depth of the relief. The perception of the size using visual and touches top up substantial accuracy.

In addition, "observed in any state ethnic processes allow us to judge about ethno-social situation, which is inextricably linked with the history of the state and iethnic policy" (Karabulatova, Shaimerdenova, Avakov \& Niyazov, 2009, p. 15). We understand that the symbolic stress on space and the name of the space at the moment of formation of the state, as such as in its moments of crisis repeatedly arises as symbolic, is a membership of the ordinary, pretheoretical mass consciousness, in many tways determines the nature of contemporary culture with a worsening religious and ethnic conflicts.

\section{Materials and Methods}

The issue of this research stipulated its interdisciplinary nature and its relationship with the various branches of the social and psychological science, sociology, cultural studies, onomastic, semiotics, architecture, painting, monumentalities, and artistic creativity in general. The research was performed on the fond of theoretical and methodological principles of the 
domestic social psychology contained in the works of A. Abulkhanova, Ananiev, A.A. Bodaleva, I.G Volkova, R.B Gitelmahera A.I. Dontsov, A.L Zhuravlev, A.I. Kitov, A.G. Kovalev, E.S. Kuzmina, B.F. Lomov, V.N. Myasishcheva, Vladimir Novikov, N.N. Obozova, B.N. Panferova V.D. Parygina, A.V. Petrovsky, K.K Platonov, Rubinstein, A.D. Sventsitsky, L.I. Umansky, E.V. Shorokhova, V.A. Yadava and others.

The research issue points to a link between the different characteristics of social and perceptual processes, objective properties of their subjects and objects that appear in a particular region. It emerged at the joint of social psychology, cultural studies, cognitive science and sociology, sociology of culture is currently strengthen credibility as an independent branch of the social and psychological science. These fundamental ideas are found in the works of Russian scientists - E.E. Vendrova, I.P. Volkov, R.B. Gitelmahera, N.V. Grishina, A.L. Zhuravlev, A.I. Kitov, A.G. Kovalev, E.S. Kuzmina. B.F. Lomov, Vladimir Novikov, K. Platonov, A.L. Sventsitsky, A.V. Filippov, E.V. Shorokhova and others.

Today "the situation of breaking paradigms, finding new spiritual values, in-depth learning of the experience of perception of life (...) becomes particularly important condition for the development of the region" (Smirnov, 2005, p. 65), so that the representatives of various directions are talking about special creation of information field, they write about it, like modern writers (Karabulatova \& Niyazov, 2014 \& Minaev, 2007). For the category of space can be used all ethnocultural potential of the human, in this case, we can agree with V.G.Kostomarovym and E.M.Vereschaginym who expressly say that a national-cultural component attaches to proper names, perhaps to a greater extent than appellatives (1990, p. 56).

The material for the exploration is based on primary and secondary materials taken in comparison. On the one hand, it is the author's observation and recording of personal interviews on the perception of the natural and cultural artifacts. On the other hand, analysis of media publications on the topic of interest, scientific developments both in Russia and abroad.

\section{Results}

In the real nature topo-space exists a differentiation in the perception of the natural landscape (proper names of spatial objects)it depends on the form of identity (the indigenous population - came to - modern migrants, representatives of the contacting and non-contacting ethnic groups in the region, region's residents and residents of other regions, etc.) virtual is from cultural and mythological identity (archetypical images of real mythology of ancient and modern people , fantasy mythology). We cannot say that an active exploitation of the mythological past is characteristic only in a real space. Maximum this is process may be presented in the virtual space, so In the Internet. For example, in the Internet-games as (Three Kingdoms, Luxor, The Horde, etc.), virtual alias (magician Tamerlane, Mother Seraphim, etc.), etc. Admittedly that mythological consciousness ascribes to things, places, sometimes they are not peculiar to quality as "myth-making has only unconsciously poetic beginning" (Meletinsky, 1995, p. 7). Avg. computer games names like "The Golden Horde", "Lion Heart", "Siberia", "Lord of the Rings: The Struggle for Middle-earth," "Prince of Persia: The Sands of Time," "Lords of War", "The New Land".

Mythological of naive linguistic consciousness, the environmental friendliness in relation to human mind have kept undercover way of topos as the enigma heart of area, particulary it is a feature of human mind using by creators of nextgeneration games, consciously, in our view, for creating a psychological dependence of users on computer games (Karabulatova, 2013, p. 795).

Modern onoma-creativity as a kind of myth finds a second life, rising to a new level of perception of the recipient. Hence we observe such a variety of proper names in various fields of nuclear and peripheral onoma-space of modern post-Soviet states, reflecting the formation of different kinds of identities. However, modern onoma-space becomes one platform where communicative war begins between: a) English and Russian (from here, in our opinion, begins a bright polarization in the name of the new microtopoobject like: Knyazhye Lake and Green House, etc.); b) between the Russian language and the official language of a country (Kabedenov - Kabedenuly, Karabulat - Karabulat - Karabulatidis, etc.); c) the official language of the CIS countries and English (Halyk Bank - Nalyk bank, so the People's Bank - and the like); d) the Russian language and the language of the republics within the Russian Federation (Bashkortostan - Bashkortostan, etc.); e) the Russian language and the language of national minorities (Amangeldyevna - Amangeldinovna - in the form of options patronymic in the same family). Such a complex communicative situation requires a balanced ethno linguistic information approach to the analysis of contemporary onomastic systems governing the border area of a particular region.

The name space as ancient informative clot in the best synthesis of the idea, revealing previously hidden cognitivecommunicative language are being spatial phenomena that confirms the idea Yu.N.Karaulova that all internal native vocabulary of speakers spread over associative network (Karaulov, 1997; Karabulatova, 2001 \& Madieva, 2005). For 
example, a sacred space can multiply: in Siberia, more than 350 holy places of Muslims called Astana. In this connection it is appropriate to remember that in Siberia Astana - is an integral part of the local cult of saints, does not recognize the Quranicbut is an important element of the so-called folk Islam, which naturally includes a variety of archaic beliefs and practices (Sayfulina \& Karabulatova, 2014 \& Karabulatova \& Sayfulina, 2015). Each Astana is surrounded by many beliefs, signs, stories (Sayfulina, Karabulatova, Yusupov \& Gumerov, 2013 \& Karabulatova \& Sayfulina, 2015). Marking the Central part of Eurasia astana, the ancient Turks designated this "the places of power" (Karabulatova, Ermakova \& Chiganova 2014).

The understanding of the holy (Acmola is a white grave, a holy grave) and sacral (Astana is the capital, but for the Siberian Tartars Astana is a sheikh's burial place, a sacral place in general) in the worldview of the Eurasian (Russian, Kazakh, Tatar, etc.) has a special meaning. The double designation of the sacred manifested in the profane world, most clearly indicates the presence of the Divine, higher power. The researchers emphasize that sacred sanctum - "it is what is on the periphery of the sacrum, which serves to complete isolation from contact with him" (Benvenist 1995: 343-350). For example, among the Siberian Tatars, whose ethnogenesis occupy a significant percentage of Kazakhs (Yusupov \& Karabulatova 2014; Zamaletdinov, Yusupov, Karabulatova, Yusupov \& Husnutdinov, 2014), widespread memorates and legends about Astana, their guardians, about the miracles and the phenomena that occur near these places. The reasons of the origin of the myths one should look at the specificity of the cultural-historical development of society. A myth is a living tissue of being, in which life is real. Today we can say that all attempts to mythologize and mystify the inner and outer world of man become a sort of consolidation of the four whales, which is the culture of modern society. In this case, the phenomenon named Astana is not only the name of the capital of Kazakhstan, but also a symbol of the Holy places in the South of the Tyumen region. In this regard, it is neccessary to mention that N. And.Nazarbayev, naming the capital of Kazakhstan "a heart of Eurasia", continues the tradition, which takes place at the Siberian Tatars and Siberian Kazakhs to designate a Holy place, a place of prayer of the heart, as Astana (Karabulatova, Ermakova, Chiganova 2014).

In the formation of new independent states, as a rule, myths are neccessary as forms of mass experiences and interpretation of reality (Lyotard, 1998 \& Lotman \& Uspensky 1973). The fragments of the Turkic world are scattered through the vast space of Eurasia as messages from our ancestors about the progress and development of Turkic culture on the Eurasian territory. The Turks didn't just make a step towards a rapprochement of the West and the East, but established their new state, connecting fragmented ancient world together. Kazakhstan, declaring himself the successor of the great ancient Eurasia, gives all of us a powerful motivation of creation, the awakening of genetic memory, which helps to create the present and the future. Finding a "heart space" in the mystical traditions of every nation is a vital step on the path of spiritual ascent. In the context of the modern history, we think, the geopolitical role of the Tyumen region as the heart of Eurasia, is the main. Here are "vessels" of pipelines connecting Europe and Asia. And in this sense, the new mythological-political slogan of United Russia, stressing that "Here is the heart of Russia!" - it is not just a metaphor, coming from seemingly coincidental shape of the Tyumen region with the human heart (remember that the shape of the modern Tyumen region similar to the heart $-\mathrm{I}$. K.), but the text with deep meaning, forcing us to reflect on the mystical role of each small country in the great destiny of the Motherland.

In the perception of space, depending on the placement of objects in space appear the visual illusions, that is an inaccurate perception of the size, parallelism, convexity, concavity, outside or inside. It is typical for the perception of natural and artificial landscapes. A pencil, immersed in a glass of water, seems to be curved; the sun in the morning and evening seems huge comparing to how it is perceived in Zenith, two of the same angle, same circle, the same lines seem among various larger or smaller images of the same items, etc.

A sculpture in modern countries is an essential element of the urban environment, it was created and is created in relation to the surrounding area in different historical-cultural types in different ways. For example, the creators of Greek naturally associated with natural space, classic town stretches for relief and all wrapped by air, did not let the location of the sculptural volumes at the geometric center of the squares. The sculptures were placed around the perimeter. For example, the famous nine-meter statue of Athena preaches has been isolated from the mainstream of the movement of people on the Athenian Acropolis. A sculpture was not subjugated the space area, but contributed to its formation. But the Romans monuments to the emperors preferred to set at the geometric centers of the squares, asserting the fact of its dominant position in the world. With this arrangement of the sculpture the space of the square is bound and retained by the volume of the statue. As for Gothic, facade here the sculpture is to beautify, diversify and strengthen the relief in the wall plane, which has lost a spatial relationship with the volume of the structure. Tightly built, leaving a disproportionate facades in a small area-the porch, Gothic cathedrals was not seen as whole volumes, but only parts. In order to avoid the monotony of the impact of the facade, Gothic masters tried to vary the wall of the Cathedral arcature, niches, and spires, including sculpture. During the Renaissance and later periods the sculpture (like the Roman) sought to establish so that its volume dominated the surrounding area. 
The interiors of the monumental buildings and exterior volumes had a variety of solutions. The Orthodox Church is a symbol of sacred space. Here takes place a reconstruction of the sacred world. In the ancient Eastern Christian churches all subordinate to a single internal space, where the dome is the sky, and the place under the dome is the earth. The temple has a soft natural sanctification. Window slits are located above eye level so as not to ruin the experience of the unity of space. The main natural light is over the heads of under the dome in the drum. The paintings are not in the temple of self-value, they are "working" on the space subject to him and connected with him. In contrast to Orthodox Catholic churches have a lot in common with the Roman forums. Not only because the area occupied by the Cathedral, not inferior in size to the area occupied by the forum, but also on the proportions of the plan and at the scenery (the Roman forum is often compared to hall, which is not enough overlap). Catholic cathedrals filled with large images. The common symbols is replaced by numerous allegorical details. The temple area is divided by the abundance of architectural and decorative elements. Huge space of the Cathedral is the ground for the tireless imagination of the artist. In Eastern Christian churches there is two-dimensional image. They don't "break" the walls surrounding the space but as noted above are submitted to him. Western Christian images on the contrary "break through" the two-dimensionality of the wall, thereby "breaking" the temple area. However, the same concerns to secular interiors, where the painting of the palaces' halls is quite self-sufficing paintings.

The main thesis of nativism says: the perception of space is "congenital". They insisted that space is primary, not derivative in relation to the sensual content of character.

The main position of genetists says: the perception of space and especially of the third dimension, depth, is a product of development, personal experience. In the understanding of genetists this meant that it was something derived, the resulting if no association, but a merge (W. Wundt) non-spatial elements - sensations, the result of gradually developing a sensor local interpretation of signs (Blumenthal, 2001).

The nativists in proof of their thesis pointed to the fact that no one had ever been able to ascertain the presence of a completely non-spatial perceptions, or feelings: each sensory quality perceived is always somewhere, i.e. in some kind of spatiality.

The main argument of genetists was the fact that the perception of space, in particular the estimation of distances, for children, for example, less perfect than for adults, and it develops with age. To solve this problem they tried to enlist the help of a pathology. Observations on the perception of space operated from blindness has shown that when a patient two days after surgery for the first time opened his eyes, he saw the "light field", a few days later - "translucent water balloons", which was the circles of light scattering from irregular accommodation. But after several weeks, the distance of visible objects was assessed in the operated patients still very inaccurate: planar and three-dimensional shapes (ring and ball) they were not distinguished; they did not understand the potential reduction of distant objects in the painting; moving objects seemed to them more rest. Normal perception of spatial properties and relations were established only gradually, step by step.

We perceive the space never wears symmetric nature; it is always more or less asymmetrically. Some items are at the top from us, others are at the bottom; ones are further, the other closer; some of them are on the right, others are on the left. Different spatial arrangement of the items in this asymmetrical space are often crucial. As an example it can be a situation where we need to understand the layout of the rooms, save the trip plan and so on. In conditions when we can rely on additional visual signals (arrangement of things in the corridors, different kind of buildings on the streets), such orientation in space is easy. When this additional visual support is eliminated, such orientation is very difficult (at exactly the same subway stations where there are two nothing in mind no different opposite output). Orientation in this asymmetrical space is so complex that some of the mechanisms described above are not enough. To provide extension mechanisms, primarily the allocation of "leading" the right hand, upon which people and performs complex analysis of external space and systems abstract spatial symbols (right - left). At a certain stage of ontogenesis, when the lead's right hand has no allocated yet, and the system of spatial concepts has not learned yet, the symmetrical side of the space continues to be confused for a long time.

Greek cities of the archaic times and the classics differ from cities founded by the Romans, by their attitude of the space in which they arise. Greek town is inseparable from the landscape. The Roman opposes itself to the landscape. For the Greeks the existing topography of the land was the basis of the forming the image of the city. From it was born the urban silhouette which did not conflict with the lines of nature, engaging with it in harmonious unity (Dionysius the Areopagite, 1994). Space classic city largely came out from the natural space. The Romans changed the existing landscape to fit their needs, aligning the area under the foundation of the city, coming into conflict with nature. The silhouettes of Roman cities are flat and their plans emphasized rational. Roman urban planning policy in relation to nature is antagonistic. The space of the city with this approach is sharply separated from the natural space. The cities of Byzantium and Ancient Russia like the ancient Greek cities and to an even greater extent, is inseparably connected with 
nature. City boundaries dissolve in it. A low but expressive silhouettes of Eastern Christian cities never collide with terrain pattern. Something average between the classical city and the city of antagonist represent Gothic cities of Europe. The medieval city and classical is tied to the existing landscape but it is confined by high walls and is not connected with the outside world. The Gothic silhouette of the city grotesquely high and sharp. His lines are alien to the lines of the surrounding nature.

In general outline you can see the cities in this way, if you stay away from them. Intra-urban space (streets, squares, courtyards) structures are formed. Here is the main role in the organization environment belongs to the architecture. Spatial laws within the city remain the same as outside. The city is filled with either air (air), and every building seems to be wrapped in them, or the buildings strictly divide the airspace of the city and stifle it, as separating from the outer world of nature and from spaces adjacent streets and squares. In the classic city the main buildings are the temples which are open from all sides. In cities with a theocentric socio-cultural dynamics they are solved as freestanding volumes. The main squares and streets of the cities of Greece, Byzantium and Russia was not surrounded by deaf residential development. They are cross-cutting. Cities themselves are naturally associated with nature, filled with greenery of gardens and groves (Kobersy et al., 2015). The city-antagonists (cities of the Roman Empire, Renaissance, Baroque) in contrast, insted of free-standing volume prefered the principle facade of the architectural solution. Their squares and streets densely lined the walls of the facades, forming their own isolated spaces. These are geometrically correct Roman forums and the Western European squares, streets and courtyards of the middle ages, Renaissance and Baroque. The space in these cities are separated from nature and cut into pieces.

Architectural and spatial forms (in particular, buildings) have a number of visually perceived properties that are important to their performance. Here is their main properties:

1. A geometric view - the main property of the form of architectural structures, it is determined by the ratio of the size of the shape in three-dimensional space (width, height, depth). If one dimension is much larger than the other two, the shape has a form of line.

2. The sizes of the architectural form is the property of its length by height, width, depth, relative to the size of a man, and in comparison with other related forms.

3. The position of a form in space relative to the viewer; frontal, profile, horizontal; closer, farther, higher, lower or the horizon line.

4. The mass of the building in the visual perception depends on visual assessment of the amount of material architectural forms. The greatest weight have cubic or spherical dense shape and a smaller hollow-core, flat and smooth.

5. The texture of the material is an important property of architectural form, reflecting the voluminous nature of the surface, while the texture (image) reflects the linear structure of the material on the surface (e.g., wood grain).

6. A color in architectural compositions - the property of a surface to reflect or emit light of different spectral properties. It is characterized by the color tone (hue), saturation (degree of lightness of a color), lightness (reflectance of the surface).

7. A chiaroscuro - property detecting the distribution of light and dark areas on the surface of the mold. The chiaroscuro enhances and facilitates visual perception of architectural form (Serov, 2004, p. 56-72).

Most detect the amount and texture of architectural form the direction of the light at an angle of $45^{\circ}$ to the horizontal and to the vertical plane. The role of natural and artificial lighting architectural-spatial composition (as a threedimensional shape, and interior) to create an artistic image is particularly important.

The qualitative characteristics of light - direct, diffuse, and reflected, relate to the orientation of the building and the condition of the natural environment. Direct light can illuminate the Southern, Eastern and Western facades of buildings, penetrating into the interior as the side or top light. It creates a joyful mood, but in working and learning spaces it blinds.

The natural light reflecting by the screens increases the illumination. A diffused light reflected from the sky does not reveal any form therefore it does not applicable in deep reliefs, however, it is convenient for the working space.

An artificial lighting of volumes of architectural structures used on the street level, main lighting and illumination of a number of monuments.

Artificial lighting of volumes of architectural structures is used on the street level, main lighting and illumination of a number of monuments. Artificial lights came on in the interior a more organic weight of lighting fixtures, fluorescent ceiling and light reflectors. The reflected light in the interior creates the illusion of ease of forms. Lighting devices in the interior sometimes acquire an independent significance, participating in solving problems of composition, highlighting the main things, which are tectonics and form (Frieling, 2003).

All the properties of architectural forms appear in their totality and unity, forming a complex composition patterns. 
Architectural composition (creation, composition) is a system of creation of the project and the entity of the architecture. Architectural composition is a complete system of architectural forms that meets the artistic, functional and technological requirements, which structures the space, combining artificial and natural landscapes.

The science of architectural composition studies the general laws of building forms in architecture and the means of achieving unity of form and content. Architects should reconcile the three sides in a harmonious composition building: on the one hand the convenience and benefits (functional task), on the other hand strength and efficiency (design and feasibility task) and beauty of form (aesthetic objective). Requirements for modern architecture scientifically justified. The science studies the peculiarities of individual types of buildings, the relationship of the premises, the equipment, the size and shape of the space required for specific social processes, lighting, acoustics. All these requirements are taken into account in the building of public and residential buildings. Choice of location for residential and public buildings in the city, the placement of the green areas with the aim of establishing the city as a single integral body with the impact of climatic and natural conditions, landscape, orientation of buildings on countries of the world are scientifically grounded.

Finally, the human psychology and physiology also impose requirements to the architectural composition of buildings. Architecture, as the human environment, affects our feelings, reflected in human consciousness, and thus involved in the formation of his inner world.

Thus, we can say that the semiotics of the modern space of human civilization in some way expresses the relation of humanity to the natural world, to the earth itself, and also contains a secondary perception of natural phenomena, represented in artificially created types, forms of artificial space.

\section{Discussion}

Jean Piaget, who, starting from different parts of geometry, allocated topological (based on the properties of intimacy, involvement, affiliation pixels), a projection (direct and save some quantitative relations) and Euclidean representations (preservation of straight lines, angles, parallelism, distance) suggested one of the first classifications of spatial representations. In Russian psychology the classification of spatial representations is based on the approach of Jean Piaget (Chentsov et al., Inshakov, Kolesnikov \& Semenovich, etc.). The alternative of considering the classification of spatial representations is the separation of different ways of orientation in space in the framework of the cognitive approach to topographical knowledge ("map display") and knowledge of the route ("map-path") (E.K. Torndike, F. HayesRoth, A. Siegel and S. white; F.N. Shemyakin).

Depth perception is closely connected with spatial representations. In the framework of the cognitive approach there are various theories regarding the content of stored information. There is a conceptual-propositional model, a radical theory of images and the theory of dual coding. The study of the perception of space is possible with the help of analysis of the facts of perceptual activity, in particular, of the drawings. Perfect picture of space is impossible (due to binocular indication of depth), so the variety of distortions during the transmission of the third dimension defines the ways of the image space. B.F. Rauschenbach allocates drawing methods (characteristic of Ancient Egypt), parallel, reverse (characteristic of the middle Ages), linear or direct perspective (which appeared in the Renaissance). Traditionally, linear perspective is accepted as the standard. Other ways of depicting space, the reverse perspective, in particular, (typical of children's drawings, as well as patients with local brain lesions) are attributable to design flaws, inadequate skills in image space. Actually there are a number of factors that explain the psychological mechanisms of reverse perspective. They include a change in the observer's point of view, the mechanism of constancy of forms, hyper constancy, spatial representation. I. e back perspective construction are caused by the peculiarities of the organization of the process of visual perception of space.

Due to the close association of the processes of perception with other mental processes it is advisable to outline a holistic perceptual mechanisms, which mutually condition other levels of mental organization. There are different options for the allocation of perceptual mechanisms in the history of psychology. There are systems of spatial ("where") and subject ("what?") view (L. Ungerleider, M. Mishkin); vision for perception and vision for action (A. Milner, M. Goodale); ambienty and focal levels of perception (B.M. Velichkovsky); perceptual system of control and identification of objects and events E.A. Sergienko et al. Based on A. Milner and M. Goodale's approach, O.A. Goncharov allocated egocentric mechanisms and conceptual perception. Egocentric perception is actively involved in the tasks of the direct control of performed movements. It is based on absolute measurements, operates in the zone of the middle space plan, relies on topological properties of objects, leads to the effect of reverse perspective. Conceptual perception is focused on the creation of a common consistent scheme of the world, therefore, is based on a relative assessment of distances (based on monocular signs of distance), an objective coordinate system (which requires a formed projection and coordinate spatial representations), determines the effect of linear perspective. 
According to one of the central tenets of cognitive science, perceptual and motor experiences are primary to the human consciousness and, according to T.G. Skrebtsova, plays a huge role in understanding the world in general, through conceptualization of intangible in terms of familiar physical interactions (Skrebtsova, 2002). This postulate finds support and confirmation in psychological studies of cognitive processes related to the pictorial forms of mental representation: sensory, perception and representation, as well as in the theory of conceptual metaphor of J. Lakoff and M. Johnson. Lakoff explores the metaphorical systematicity, illustrating the coherence of orientational metaphors and their physical determinism and cultural experience of the individual, noting that although the polar opposition of the "top bottom", "inside outside", etc. are physical, based on orientational metaphors can vary from culture to culture (Lakoff, 1980). For example, in some cultures the future is ahead of us and in others it is behind us (as in Chinese one). Thus, apperception, i.e the perception, mediated by past subjective experience of the individual, relates to the metaphorization, caused by the presence of metaphors empirical grounds.

Antique atomists thought of space as something empty, which was the movement of atoms. Unlike Descartes, who lived in the seventeenth century and identified the space with the body and considered them a single substance, preventing any voids. Aristotle, who lived in the fourth century BC, saw the body in relation to space as a primary datum. After two thousand years Newton developed the theory of absolute space, where the body is not just secondary to him but "born" from it. However, the contemporary of Newton, Leibniz did not admit the existence of any space without the existence of bodies and in that respect returned to Aristotle's vision of problems. The question of space as it is, in other words, its substantialness, is in the speculative plane, and today, this problem, as in the last Millennium, remains unresolved. Most likely, people will never get the simple answer to it.

However, unlike the substantial problem of space, the problem of conceivable space has a specific nature that is directly connected with the perception of the world around us. Here the space is a place that can accommodate or be accommodated in any way. It cannot be imagined in isolation from the subject, as it is impossible to present the object in isolation from space. Both are inseparably linked (Lyotard, 1997).

In human representation the starting point of thinking about space, although not always conscious, probably, it is necessary to consider the position of the Earth (as a subject) in relation to the sky (space). "In this visible world, writes St. Augustine, there are two parts: the heaven and the earth; this brief notation covers all created beings". In the words of St. Augustine marked dialectical thought about the simultaneous juxtaposition and connection of space and subject matter. At this stage of thinking complete dependence of the earth (as a subject) from the sky (space) becomes apparent. The space is primarily conceived vertically top and bottom - the sky and the earth. The next stage of thinking is associated with the horizon, sunrise and sunset - another subject that is moving in space.

The diversity of the objective world is shrouded in celestial space - the sun and the moon, stars, clouds, hills, ravines, rivers and lakes, forests and meadows, animals and birds. All the sensual world spatially represents a single picture of the Universe. This picture is nothing like nature (Ferris, 2007). It is balanced and harmonious. All the items in it are mounted each in its place. Even should the existing conflicts within it maintain this balance. Humanity is also part of the objective world, enveloped by the sky. But it came from the nature and became independent. It opposed itself to the nature and entered into a dialogue with it. But humanity is not just one person, and, therefore, not one opinion. There was Abel and Cain. There was Japheth and Shem. And there was Ham...

People are organized in society and here public opinion has a critical importance. Teaming up in the social systems, people localize from other nations, both geographically and spiritually representing a logical-semantic unity. Space and ideological paradigm become the main factors determining the mentality of the people. Relation to the surrounding space, to the nature consists of a hierarchy of spiritual values of society. For one social system, the nature is the world, that God created, where man is a visitor who is forced to reckon with the established state of things. This cultural-historical type characterizes the centricity of consciousness. The space is imagined to be sacred or divine. For the mentality of the other cultural-historical type the nature is the area in which there is an opportunity to dwell in, while using the space as efficiently as possible in personal needs (Jensen, 2004). In this situation people do not regard themselves as guests, they are the hosts. Here is an extreme anthropocentrism, not the deity - humanity is the alpha and omega of existence.

\section{Conclusion}

In General, the space, or rather, what's behind the name of the spatial locus, the concept of space, acts as incomprehensibly complex system. Toponymic legends are based on associative perception. In this regard, the mental space own behalf is of particular interest because, functioning in a multi-ethnic environment, all elements of the regional system of culture are influenced by the standards of stereotypes of perception, inherent in the person as the subject of 
cognition. Society decides how to treat the world around him. And the expression of a relationship are the works of his hands. Organised into a single social system, people create settlements. Basing the settlement, they alter the space. Gradually growing, settlements turned into cities. The city is a great creation, the creation of which worked for thousands of people of different classes and ages from generation to generation. He can rightly be called a truly national work of art. It is in the form of the city in the first place, the society demonstrates its relation to the surrounding space (Simmonds, 2005).

The nation, in which the notion lives, that it with its entire urban culture is more like a guest in a God-created nature, refers to the space, as something remarkably important and holy. People in such a society are afraid to disrupt communication of the objective world. Space, flowing freely from volume to volume, envelops and binds the living world of nature with the world, artificially created by man, reviving it and filling the space with meaning. And even where the space to be fenced on all sides by walls of buildings, it becomes a reflection of the divine space of nature, which so the same stored communications and the integrity of the symbolic order. On the contrary, a society in which living relationship with the divine breaks, the community in which norm attitude toward nature as something subservient relies, changing the attitude to the space. It loses its sacred character and ceases to bind the city with the surrounding (Barabanov, 2007).

Space is the main problem in the development of theories related to human creativity. Herein lies the key to the understanding of the relationships between various functionally-integrated elements of human culture. And links, both of a formal nature, and ideas and contents. It is possible that in this plane lies the answer to the question why it is the ancient and traditional monuments of culture which produce such a holistic impression of how deep the researcher and the layman.

\section{References}

Anderson, B. (2001) Imagined communities. Reflections on the origin and spread of nationalism. TRANS. eng. V. Nikolaev; Preface by. PT.With.The Bankovskaya. M.: Kanon-Press-TS, Kuchkovo pole.

Barabanov, A. (2007) Semiotic foundations of the artistic language of architecture. In: Man and the city: space, form, meaning. Yekaterinburg: Architect.

Benveniste, E. (1995) Dictionary of Indo-European social terms. M.: Progress-Univers. pp. 343-350.

Blumenthal, Arthur L. (2001) A Wundt Primer: The Operating Characteristics of Consciousness. Chapter Four in Reiber, Robert W. and Robinson, David K. Wilhelm Wundt in History: The Making of a Scientific Psychology. Kluwer Academic Publishing.

Damn, L.F. (2007) Levels semiotization space and visual codes. In: Man and the city: space, form, meaning. - Yekaterinburg: Architect. pp. 260

Gilazov, T.Sh, Karabulatova, I.S., Sayfulina, F.S., Kurakova, Ch.M. \& Gulphiya, M. Talipova (2015) Between the East and the West: the Phenomenon of Tartar Literary Criticism in the Lingvo-Cultural Aspect. In the Mediterranean Journal of Social Science. 2015. Vol 6, No3, S2, May 2015. pp.:508-517.

Deleuze, G. (1998) difference and repetition. St. Petersburg.

Dionysius The Areopagite. The divine names. About mystical theology (1994). St. Petersburg: Peterburgskoe Vostokovedenie.

The R. Jensen, the dream Society (2004). St. Petersburg.

Karabulatova, I.S. (2001) Regional ethnolinguistics: contemporary ethnolinguistically the situation in the Tyumen region. Tyumen: publishing house of TSU. pp. 172.

Karabulatova, I.S. (2008) Prognostic toponymy: the transformation of toponymic space in the linguistic consciousness of speakers of the Russian language]. Tyumen: Printer.

Karabulatova, I.S., Shaimerdenova, N.W., Avakova, R.A. \& Niyazov, G.M. (2009) Ethnolinguistics Eurasian continuum: theory and practice. Moscow: HSE.

Kobersy, I., Barmuta, K., Muradova, S., Dubrova, L., \& Shkurkin, D. (2015). The System of the Methodological Principles of Management of Enterprise Development. Mediterranean Journal Of Social Sciences, 6(3 S4), 25. Retrieved from http://www.mcser.org/ journal/index.php/mjss/article/view/6707

Karabulatova, I.S. (2013) The problems of linguistic modeling of new Eurasian linguistic personality in multilinguistic and mental environment (by example of onomasphere). In the: Middle-East Journal of Scientific Research 17 (6): 791-795.

Karabulatova, I.S., Fedorova, E.A. \& Sayfulina, F.S. (2014) A Linguo-Mythological Space of the Toponym "Siberia" in Contemporary Slavonic Linguistic Consciousness. In the: World Applied Sciences Journal 30 (9): 1134-1138.

Kobersy, I., Karyagina, A., Karyagina, O., \& Shkurkin, D. (2015). Law as a Social Regulator of Advertisement and Advertising Activity in the Modern Russian Information Space. Mediterranean Journal Of Social Sciences, 6(3 S4), 9. Retrieved from http://www.mcser.org/journal/index.php/mjss/article/view/6705

Karabulatova, I.S., E.N. Ermakov,a \& Chiganova G.A. (2014) Astana in Kazakhstan and Astana in Siberia as a form of national Islam of Eurasia in the Linguistic-cultural aspect. In the: Terra Sebus: Acta Musei Sabesiensis, Special Issue, 2014, pp. 15-30.

Karabulatova, I.S. \& Sayfulina, F.S. (2015) Mytholinguistic Interpretation of Sacral Toponym Astana in Sociocultural Practice of the Siberian Tatars. In the: Asian Social Science, Vol11, No. 5, pp.: 303-310.

Karaulov, Yu.N. (1987) Russian language and linguistic personality. M.: Nauka. 
Karaulov, Yu.N. (1993) Associative grammar of the Russian language. Moscow: Russian language.

Lakoff, G. Metaphors (1980) We Live by. M : Johnson ; Chicago : Univ. of Chicago Press.

The Sublime and the avant-garde (1997). In the: Metaphysical investigations. Vol.4. Culture. St. Petersburg.

The Lyotard (1998) the postmodern Condition. M.

Lotman, Yu.M. (1973) Uspensky Myth - name - culture. In the: Writings on semiotic. Tartu. Vol.6, pp. 282-305.

Frieling G. (2003) Man - color - space. M.: ART Press.

Madieva, G.B. (2005) Onomastic space of modern Kazakhstan: structure, semantics, precedentiality, lemmatization. ADD. Almaty.

Meletinsky, E.M. (1995) Poetics of myth. 2-e Izd., reprint. M.: Eastern. Literature, School "Languages of culture".

Minaev, S. (2007) Media sapiens. A tale Of the third period. Moscow: Astrel.

Potebnya, A.A. (2000) Symbol and myth in popular culture. M: Maze.

Sayfulina, F.S., Karabulatova, I.S., Yusupov, F.Yus. \& Gumerov, I.G. (2013) Contemporary issues of textual analysis of Turkic-Tatar literary monuments of Western Siberia. In the: World Applied Sciences Journal Issue 27 (Education, law, economics, language and communication): $492-496$.

Sayfulina, F.S. \& Karabulatova, I.S. (2014) European Studies of Barabian Tatar Folklore: The role of investigations of the German scientist V.V. Radlov. In the Life Science Journal, 4; 11 (9s): 116-119.

Kobersy, I., Novikov, V., Shkurkin, D., \& Borisova, A. (2015). Investigation of the scope of intellectual services in the aspect of virtualizationand information economy of modern Russia. Mediterranean Journal Of Social Sciences, 6(5 S3).

Simmonds, D.O. (2005) Landscape and architecture. - M.: Stroiizdat, 2005. pp. 193.

Serov, N. (2004) In. Colour culture: psychology, cultural studies, physiology. - SPb.: Speech. pp. 627.

Skrebtsova, T.G. (2002) metaphors of contemporary Russian foreign policy discourse. In: Respectus philologicus. No. 1.

Smirnov, V.V. Sacred topos in the worldview of the population of the South of Western Siberia. In: the Living tradition of the conspiracy Siberia: Sacral-ritual discourse voodoo practices. Under the editorship of I.S. Karabulatova. St. Petersburg: Aletheia, 2009. Pp. 64-82.

Vereshchagin, E.M. \& Kostomarov, V.G. (1990) Language and culture: linguistic and cultural studies in teaching Russian as a foreign language. M: OC.

Yusupov, F.Yu. \& Karabulatova, I.S. (2014) Some results of the research system-synchronous modern dialect of the Tatar language. In the Life Science Journal 2014; 11 (7s): 246-250.

Zamaletdinov, R.R., Yusupov, F.YU., Karabulatova, I.S., Yusupov, A.F. \& Husnutdinov, D.H. (2014) The formation of tatar ethnic groups in the southern urals and trans ural region. In the Life Science Journal. 11(11s): 214-217. 